\title{
Individual risk assessment for intracranial haemorrhage during thrombolytic therapy
}

\author{
Maarten L Simoons, Aldo P Maggioni, Genell Knatterud, Jeffrey D Leimberger, Peter de Jaegere, Ron van Domburg, \\ Eric Boersma, Maria Grazia Franzosi, Rob Califf, Rolf Schröder, Eugene Braunwald
}

\section{Summary}

Thrombolytic therapy improves outcome in patients with myocardial infarction but is associated with an increased risk of intracranial haemorrhage. For some patients, this risk may outweigh the potential benefits of thrombolytic treatment. Using data from other studies, we developed a model for the assessment of an individual's risk of intracranial haemorrhage during thrombolysis.

Data were available from 150 patients with documented intracranial haemorrhage and 294 matched controls. 49 patients with intracranial haemorrhage and 122 controls had been treated with streptokinase, whereas 88 cases and 148 controls had received alteplase. By multivariate analysis, four factors were identified as independent predictors of intracranial haemorrhage; age over 65 years (odds ratio $2 \cdot 2$ [95\% Cl 1.4-3.5]), body weight below $70 \mathrm{~kg}(2 \cdot 1[1 \cdot 3-3 \cdot 2])$, hypertension on hospital admission (2.0 [1.2-3.2]), and administration of alteplase (1.6 [1.0-2.5]).

If the overall incidence of intracranial haemorrhage is assumed to be $0.75 \%$, patients without risk factors who receive streptokinase have a $0.26 \%$ probability of intracranial haemorrhage. The risk is $0.96 \%, 1.32 \%$, and $2.17 \%$ in patients with one, two, or three risk factors, respectively. We present a model for individual risk assessment that can be used easily in clinical practice.

Lancet 1993; 342: 1523-28

Thoraxcenter, Erasmus Unlversity and Unlversity Hospltal, Rotterdam, Netherlands (Prof M L Simoons MD, P de Jaegere MD, $R$ van Domburg $M S, E$ Boersma $M S$ ); Istituto dl Ricerche Farmacologlche "Marlo Negrl", Milan, Italy (A P Maggioni MD. M G Franzosi PhD, on behalf of GISSI investigators); Department of Cardlology, Duke Unlversity, Durham, North Carollna, USA (J D Leimberger $P h D, R$ Califf $M D$, on behalf of TAMI investigators); Free Unlverslty of Berlin, Germany (Prof R Schröder MD, on behalf of ISAM investigators); Maryland Medical Research Institute, Baltimore, USA (G Knatterud PhD, on behalf of TIMI investigators); and Brigham and Women's Hospltal, Boston, Massachusetts, USA (Prof E Braunwald MD, on behalf of TIMI investigators)

Correspondence to: Prof Maarten L Simoons, Thoraxcenter, University Hospital, PO Box 1738, 3000 DR Rotterdam, Netherlands

\section{Introduction}

Thrombolytic therapy improves immediate and long-term survival ${ }^{1-4}$ and quality of life ${ }^{5}$ in patients with evolving myocardial infarction; however, it also carries a small but significant risk of severe bleeding complications, including intracranial haemorrhage. A physician must decide for each individual patient whether the potential benefits of thrombolytic therapy ${ }^{6}$ outweigh the risk. Previous studies have shown that age, hypertension, a high dose of thrombolytic for a given body weight, being female, previous central nervous system disease, and use of oral anticoagulants are associated with increased bleeding risk after thrombolytic therapy..$^{7-12}$ However, the numbers of patients in each of these studies are small and risk assessment in individual patients remains uncertain.

In this report, data from several studies ${ }^{7-11,13-23}$ were combined to collect a larger database for statistical evaluation, so that we could develop a risk profile for intracranial haemorrhage that can be applied to individual patients to assess the appropriateness of thrombolytic therapy.

\section{Patients and methods}

Individual patient data were collected from five sources: a registry of thrombolytic therapy in the Netherlands in $1988-90,{ }^{10}$ combined with data from two studies by the European Cooperative Study Group, ${ }^{10,16,17}$ and for participants in the GISSI-II and International Study Group trials, ${ }^{11,13,14}$ the TIMI II trials, ${ }^{7,8,18,19}$ studies by the TAMI group, ${ }^{9,20-23}$ and the ISAM study. ${ }^{15}$

In the Netherlands 2469 patients receiving thrombolytic therapy in 61 hospitals were registered prospectively during 18 months in 1988-90. The registry sought to collect all patients who received thrombolytic therapy for evolving myocardial infarction. ${ }^{10}$ No specific entry or exclusion criteria and no formal criteria for administration of thrombolytic therapy were applied. However, treatment of patients aged 75 years and older and treatment starting later than $6 \mathrm{~h}$ after symptom onset was unusual at that time. Most patients received streptokinase, usually with aspirin and intravenous heparin. 24 patients were identified who developed intracranial haemorrhage within $48 \mathrm{~h}$ of the start of thrombolytic therapy, and complete data were available for 22 of them. We also included 2 patients who had intracranial haemorrhages at the Thoraxcenter, Rotterdam, and 7 patients of 722 treated with alteplase in two studies by the European Cooperative Study Group. ${ }^{16,17}$ Full details have been presented elsewhere. ${ }^{10}$

In the GISSI-2 and International Studies, complete data were available for 20768 patients who were randomly assigned either 1.5 MU streptokinase or $100 \mathrm{mg}$ alteplase. That study had no age limit but patients with a history of cerebrovascular events in the preceding 6 months were not eligible. ${ }^{13}$ All patients received aspirin and half received subcutaneous heparin, starting $12 \mathrm{~h}$ after initiation of thrombolytic therapy. Strokes were reported in 236 patients $(1 \cdot 14 \%)$, of which 100 were of embolic origin, 74 were haemorrhagic, and 62 could not be classified. ${ }^{11}$ 


\begin{tabular}{|c|c|c|c|c|c|c|c|c|c|c|c|c|}
\hline & \multicolumn{2}{|c|}{ NL and ECSG } & \multicolumn{2}{|l|}{ GISSI-2 } & \multicolumn{2}{|l|}{$\mathrm{mm}$} & \multicolumn{2}{|l|}{ TAMI } & \multicolumn{2}{|l|}{ ISAM } & \multicolumn{2}{|c|}{ Combined trials } \\
\hline & $\mathrm{ICH}$ & $c$ & $\mathrm{ICH}$ & $\mathrm{C}$ & $\overline{\mathrm{ICH}}$ & $c$ & $\mathrm{ICH}$ & $\mathrm{C}$ & $\mathrm{ICH}$ & C & $\mathrm{ICH}$ & C \\
\hline n & 31 & 62 & 74 & 142 & 27 & 54 & 14 & 28 & 4 & 8 & 150 & 294 \\
\hline No (x) mais & $27(57)$ & $48(77)$ & $47(63)$ & $112(79)$ & $16(60)$ & $43(80)$ & $7(50)$ & $23(87)$ & $2(50)$ & $\overline{66(75)}$ & $98(65)$ & $52(79)$ \\
\hline Moan (SD) ofte In yr & $65(8)$ & $\overline{58(10)}$ & $66(11)$ & $60(12)$ & $63(8)$ & $\overline{56(9)}$ & $65(7)$ & $\overline{54(12)}$ & $63(8)$ & $\overline{58(12)}$ & $65(8)$ & $58(11)$ \\
\hline \multicolumn{13}{|l|}{ Infarct location* } \\
\hline Anterior & 14 & 19 & 25 & 59 & 15 & 30 & 5 & 11 & 3 & 3 & 62 & 122 \\
\hline Inferior & 16 & 38 & 12 & 26 & 12 & 24 & 9 & 17 & 1 & 5 & 50 & 110 \\
\hline Inferoposterior & 10 & 24 & .. & .. & .. & .. & .. & .. & $\therefore$ & .. & 10 & 24 \\
\hline Lateral & 5 & 11 & .. & & .. & .. & .. & .. & .. & .. & 5 & 11 \\
\hline Unknown & 1 & 3 & 37 & 57 & .. & .. & .. & .. & .. & .. & 38 & 60 \\
\hline \multicolumn{13}{|l|}{ Thrombolytic drug } \\
\hline Streptokinase & 15 & 35 & 30 & 79 & & . & $\cdots$ & .. & 4 & 8 & 49 & 122 \\
\hline Alteplase & 10 & 20 & 44 & 63 & 27 & 54 & 7 & 11 & & .. & 88 & 148 \\
\hline (pro-)Urokinase & 3 & 6 & . & .. & . & .. & 4 & 6 & .. & .. & 7 & 12 \\
\hline Alteplase + urokinase & .. & .. & . & .. & .. & & 3 & 11 & .. & .. & 3 & 11 \\
\hline Anistrepiase & 3 & 1 & . & .. & .. & .. & .. & - & . & .. & 3 & 1 \\
\hline
\end{tabular}

$\mathrm{NL}$ = Netherlands Registry; ECSG = European Cooperative Study Group:10 GISSI-2 = Gruppo Italiano per io Studio della Soprawivenza nell 'infarto Mipcardico B and the international Study

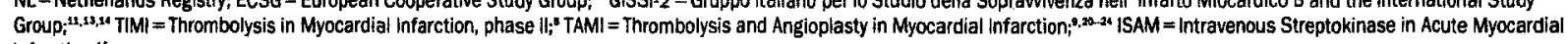
infarction. ${ }^{15}$

"Different criteria were used by the various study groups; in some patients multiple infarct locations were reported simultaneously.

Table 1: Baseline data for 150 patients with intracerebral haemorrhage (ICH) and 294 matched controls (C)

In the TIMI phase II pilot study and clinical trial, 908 patients were treated with $150 \mathrm{mg}$ alteplase and 3016 patients with $100 \mathrm{mg}$ alteplase, both in combination with heparin and aspirin. ${ }^{18,19}$ Intracranial haemorrhages were observed in 27 patients (23 intracerebral, 4 subdural ${ }^{18}$ ), of whom 14 had received $150 \mathrm{mg}$ alteplase and 13 had received $100 \mathrm{mg}$. The TIMI studies enrolled patients up to the age of 75 years. Initially, patients with a history of active cerebrovascular disease during the previous 6 months were not eligible. After revision of the protocol, ${ }^{7}$ all patients with a history of stroke were excluded, as well as patients with blood pressures above $180 \mathrm{~mm} \mathrm{Hg}$ systolic or $110 \mathrm{~mm} \mathrm{Hg}$ diastolic at presentation. At first, aspirin $80 \mathrm{mg}$ was started on the same day as thrombolytic therapy. The protocol was revised, and in most patients (3297) aspirin was not started until the next day. Heparin was given as a 5000 IU bolus at the start of alteplase infusion, and continued at $1000 \mathrm{IU}$ per $\mathrm{h}$. Subsequently, the dose was adjusted to maintain the activated prothrombin time (APTT) between 1.5 and 2.0 times control. After day 6 , intravenous heparin was replaced by subcutaneous heparin and aspirin was increased to $325 \mathrm{mg}$ daily..$^{8,15,16}$

The TAMI studies ${ }^{9,20-23}$ enrolled 1619 patients up to 75 years of age, excluding those with recent ( 6 months) trauma, recent major surgery or active internal bleeding, known structural brain disease including tumour or arteriovenous malformation, stroke within the previous 6 months, and uncontrolled hypertension (diastolic pressure $>120 \mathrm{~mm} \mathrm{Hg}$ by several measurements). Strokes were reported in 31 patients, 14 of whom had intracranial haemorrhage $(0.9 \%$ of all patients). Thrombolytic therapy consisted of alteplase, in doses of $64-150 \mathrm{mg}$, plus urokinase $(1 \cdot 5-2 \cdot 0 \mathrm{MU})$ or $3 \mathrm{MU}$ urokinase alone in some of the patients. Heparin infusion was started during diagnostic and interventional cardiac catheterisaton, and maintained continuously for a minimum of $24 \mathrm{~h}$, adjusted to maintain APT'T between 1.5 and 2.0 times baseline. Aspirin was started during thrombolytic therapy and continued at $325 \mathrm{mg}$ daily together with dipyridamole $75 \mathrm{mg} 3$ times daily.

The ISAM study ${ }^{15}$ enrolled 1741 patients. The age limit was 75 years. Reasons for exclusion were known haemorrhagic diathesis, use of anticoagulants, severe treatment-resistant hypertension (systolic $\geqslant 200 \mathrm{mg} \mathrm{Hg}$, diastolic $\geqslant 120 \mathrm{~mm} \mathrm{Hg}$ ), trauma, stroke, acute headache, visual disorders of unknown origin, trauma, or increased gastrointestinal bleeding risk. Intracranial haemorrhage was reported in 4 patients. All patients received streptokinase 1.5 $\mathrm{MU}$ in $1 \mathrm{~h}$, as well as methylprednisolone, intravenous aspirin 500 $\mathrm{mg}$ and heparin, followed by phenprocoumon for at least 3 weeks.

For each patient in these studies with intracranial haemorrhage, 2 controls were selected from the same population. The controls were patients treated in the same hospital, immediately before and after each patient with intracranial haemorrhage. For all cases and controls we recorded sex, age, body weight, the presence of insulin-dependent diabetes mellitus, vascular disease (history of intermittent claudication or vascular bruits before admission), hypertension before admission (patients receiving at least one antihypertensive drug), the use of anticoagulants before admission, smoking status, hypertension on admission (systolic $\geqslant 165 \mathrm{~mm} \mathrm{Hg}$, diastolic $\geqslant 95 \mathrm{~mm} \mathrm{Hg}$, or both). We also recorded whether the patient received heparin, antiplatelet drugs, and anticoagulants during the hospital stay.

Differences in clinical characteristics between patients with intracranial haemorrhage and controls were expressed as crude or univariate odds ratios with $95 \%$ CI. Multivariate logistic regression analysis was done with the BMDP statistical package. All variables and interaction terms were entered into the model.

\begin{tabular}{|c|c|c|c|c|c|c|c|c|c|}
\hline & \multicolumn{3}{|c|}{ All patients } & \multicolumn{3}{|c|}{ Alteplase-treated paltents } & \multicolumn{3}{|c|}{ Streptoklnase-treated patlents } \\
\hline & $\mathrm{ICH}+$ & $\mathrm{ICH}-$ & $\begin{array}{l}\text { Odds ratio } \\
(95 \% \mathrm{Cl})\end{array}$ & $\mathrm{CH}+$ & $\mathrm{ICH}-$ & $\begin{array}{l}\text { Odds ratio } \\
\text { (95\% Cl) }\end{array}$ & $\mathrm{ICH}+$ & $\mathrm{ICH}-$ & $\begin{array}{l}\text { Odds ratio } \\
(95 \% \mathrm{Cl})\end{array}$ \\
\hline $\begin{array}{l}\text { Age }>65 \mathrm{yr} \\
\text { Weight < } 70 \mathrm{~kg} \\
\text { Female } \\
\text { Previous hypertension } \\
\text { Hypertension in hospital } \\
\text { Vascular disease } \\
\text { Diabetes } \\
\text { Smoking } \\
\text { History of coumadin treatment } \\
\text { Coumadin in hospital } \\
\text { Aspirin in hospital } \\
\text { Heparin in hospital } \\
\end{array}$ & $\begin{array}{c}82 / 173 \\
76 / 171 \\
52 / 113 \\
63 / 158 \\
49 / 108 \\
6 / 12 \\
19 / 52 \\
58 / 208 \\
5 / 8 \\
6 / 31 \\
46 / 171 \\
70 / 203 \\
\end{array}$ & $\begin{array}{r}68 / 270 \\
74 / 272 \\
98 / 330 \\
84 / 270 \\
100 / 334 \\
65 / 202 \\
129 / 386 \\
88 / 218 \\
71 / 218 \\
54 / 151 \\
41 / 78 \\
39 / 118 \\
\end{array}$ & 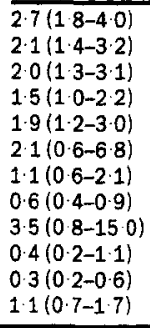 & $\begin{array}{c}52 / 93 \\
51 / 99 \\
39 / 67 \\
42 / 99 \\
27 / 56 \\
4 / 8 \\
11 / 31 \\
35 / 120 \\
3 / 13 \\
29 / 118 \\
50 / 144\end{array}$ & $\begin{array}{l}42 / 166 \\
43 / 160 \\
55 / 192 \\
51 / 151 \\
66 / 202 \\
45 / 142 \\
82 / 226 \\
56 / 126 \\
50 / 152 \\
33 / 97 \\
26 / 48 \\
18 / 49\end{array}$ & $\begin{array}{l}3.7(2.2-6.4) \\
2.9(1.7-4.9) \\
3.5(1.9-6.2) \\
1.4(0.9-2.4) \\
1.9(1.1-3.5) \\
2.2(0.5-9.0) \\
1.0(0.4-2.1) \\
0.5(0.3-0.9) \\
0.6(0.2-2.3) \\
0.3(0.1-0.6) \\
0.9(0.5-1.8)\end{array}$ & $\begin{array}{c}25 / 75 \\
25 / 71 \\
12 / 44 \\
19 / 57 \\
19 / 48 \\
1 / 3 \\
7 / 20 \\
20 / 83 \\
3 / 6 \\
2 / 17 \\
15 / 47 \\
16 / 49\end{array}$ & $\begin{array}{l}25 / 96 \\
25 / 100 \\
38 / 127 \\
29 / 108 \\
31 / 123 \\
15 / 48 \\
42 / 148 \\
29 / 84 \\
17 / 55 \\
16 / 42 \\
11 / 23 \\
19 / 66\end{array}$ & $\begin{array}{l}1.4(0.7-2.8) \\
1.6(0.8-3.2) \\
0.8(0.4-1.9) \\
1.4(0.7-2.7) \\
1.9(1.0-3.9) \\
1.1(0.1-13.1) \\
1.4(0.5-3.6) \\
0.6(0.3-1.2) \\
2.2(0.4-12.2) \\
0.2(0.0-1.1) \\
0.5(0.2-1.4) \\
1.2(0.5-2.7)\end{array}$ \\
\hline
\end{tabular}

$\mathrm{CH}+=$ the number of intracranial haemorrhages among patients with a characteristic and $\mathrm{ICH}-=$ the number in patients without that characteristic

Table 2: Distribution of rlsk factors for intracranlal haemorrhage, incidence of intracranial haemorrhage, and unadjusted odds ratios 


\begin{tabular}{|c|c|c|c|}
\hline . & $\mathrm{ICH}+$ & $\mathrm{ICH}-$ & $\begin{array}{l}\text { Adjusted odds } \\
\text { ratio ( } 95 \% \text { CI) }\end{array}$ \\
\hline $\begin{array}{l}\text { Age }>65 \mathrm{yr} \\
\text { Weight }<70 \mathrm{~kg} \\
\text { Hypertension on admission } \\
\text { Aiteplase }\end{array}$ & $\begin{array}{l}77 / 168 \\
76 / 170 \\
46 / 100 \\
93 / 258\end{array}$ & $\begin{array}{l}66 / 261 \\
67 / 259 \\
97 / 325 \\
50 / 171\end{array}$ & $\begin{array}{l}2 \cdot 2(1 \cdot 4-3 \cdot 5) \\
2 \cdot 1(1 \cdot 3-3 \cdot 2) \\
2 \cdot 0(1 \cdot 2-3 \cdot 2) \\
1 \cdot 6(1 \cdot 0-2 \cdot 5)\end{array}$ \\
\hline
\end{tabular}

Table 3: Incidence of intracranlal haemorrhage and adjusted odds ratios in $\mathbf{4 2 9}$ patients with complete data

With step-up and step-down procedures we selected the variables that contributed independently to the risk of intracranial haemorrhage $(p<0.05)$. The initial analysis included all patients with complete data sets to detect independent risk factors. Subsequently, the analysis was done with the larger number of patients for whom data on the risk factors retained in the initial analysis were complete. Data were presented as adjusted odds ratios with corresponding $95 \%$ CI. By Bayes' rule, probabilities were calculated for intracranial haemorrhage in four patient groups with no, one, two or three risk factors, respectively. ${ }^{24}$

\section{Results}

Data were available for 150 patients with intracranial haemorrhage and 294 matched controls. The other 6 control patients had incomplete data. The series consisted of 145 patients with intracerebral bleeding and 5 with subdural haematoma. Diagnosis of intracranial haemorrhage was confirmed by computed tomography in most patients, and in others by necropsy or clinical findings. The mean age was significantly higher $(p<0.00001)$ in the patients with intracranial haemorrhage than in the controls (table 1 ). There was also a significant difference between the groups in the proportion of women $(p=0.002)$. Infarct location was classified in different ways by the four study groups. Nevertheless, we found no differences in infarct location between the patient groups. In particular, no excessive bleeding risk was apparent in patients with anterior infarction. The incidence of documented intracranial haemorrhage was $0.9(0 \cdot 6-1 \cdot 3) \%$ in the registry from the Netherlands, $1.0 \%$ in the two trials by the European Cooperative Study Group, $0.4 \%$ in the GISSI-2 and International Studies (with another $0.3 \%$ unclassified strokes), $1.5 \%$ in TIMI patients receiving $150 \mathrm{mg}$ alteplase and $0.4 \%$ in those receiving $100 \mathrm{mg}$ alteplase, $0.9 \%$ in the TAMI studies, and $0.5 \%$ in the ISAM study. Our study could not investigate the risks of intracranial haemorrhage with all the thrombolytic regimens included. Nevertheless,

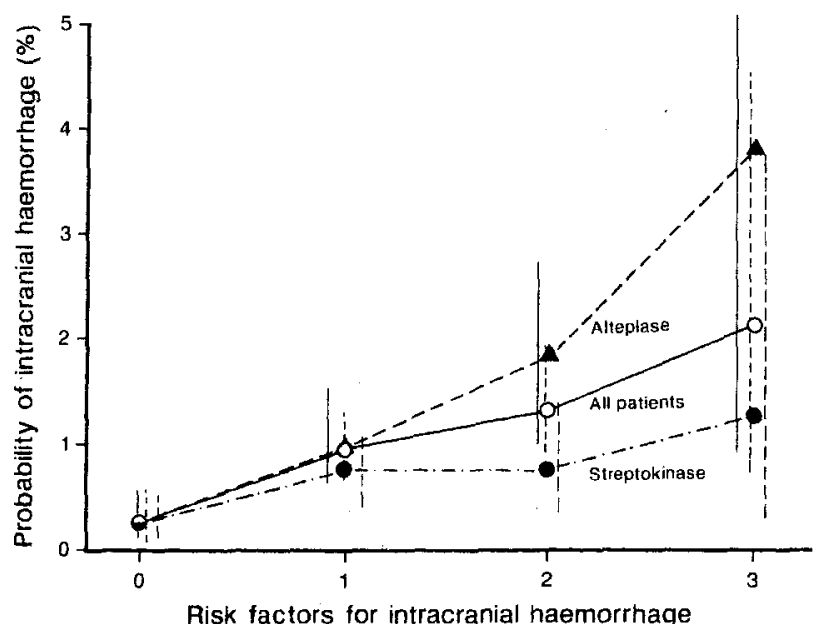

Figure: Probability of intracranial haemorrhage in patlents with 0,1 , or 3 risk factors

vertical bars $=95 \% \mathrm{Cl}$.

\begin{tabular}{|c|c|c|c|c|}
\hline \multirow[t]{2}{*}{$\begin{array}{l}\text { Risk } \\
\text { factors* }\end{array}$} & \multirow[t]{2}{*}{$\begin{array}{l}\text { Incidence } \\
(\%) \dagger\end{array}$} & \multirow[t]{2}{*}{$\begin{array}{l}\text { Whelihood } \\
\text { ratiof }\end{array}$} & \multicolumn{2}{|c|}{$\begin{array}{l}\text { Probablilty of Intracranlal bleedling } \\
(95 \% \mathrm{Cl}) \text { in } \%\end{array}$} \\
\hline & & & Incidence $=0.50$ & Incidence $=0.75$ \\
\hline $\begin{array}{l}0 \\
1 \\
2 \\
3\end{array}$ & $\begin{array}{r}53 \\
31 \\
15 \\
1\end{array}$ & $\begin{array}{l}0.34 \\
1.28 \\
1.77 \\
2.89\end{array}$ & $\begin{array}{l}0.17(0.10-0.27) \\
0.64(0.47-0.88) \\
0.88(0.60-1.28) \\
1.43(0.61-3.31)\end{array}$ & $\begin{array}{l}0.26(0.15-0.41) \\
0.96(0.70-1.32) \\
1.32(0.92-1.91) \\
2.17(0.92-4.83)\end{array}$ \\
\hline
\end{tabular}

*Risk factors: age $\geqslant 65$ years, body weight $<70 \mathrm{~kg}$, hypertension on admission, and the use of an alteplase regimen. $†$ Derived from studies by European Cooperative Study Group. ${ }^{16,17}$ $\$$ Probability of finding the risk profile among patients with intracranial bleeding divided by probability of finding the same risk profile among patients without intracraniai bleeding. Probability of intracranial bleeding was calculated from overall incidence and likelihood ratio with Bayes' rule.

Table 4: Probability of intracranial haemorrhage after a

thrombolytic regimen as used in these studles

it was apparent that a greater proportion of patients who had intracranial haemorrhages had received alteplase in various doses, whereas more controls had received streptokinase (table 1).

The distribution of possible risk factors for intracranial haemorrhage is given in table 2 . Advanced age, low body weight, female sex, and high blood pressure were associated with an increased risk of intracranial bleeding. Among the five patient series trends were similar, although many were not statistically significant within different series because of small patient numbers. Odds ratios were greater than 2.0 in all series for age and body weight and in 4 of 5 for female sex. Few patients were taking coumadin or had a history of peripheral vascular disease, and no significant association with intracranial bleeding could be detected. Smoking was associated with a reduced intracranial bleeding risk. Furthermore, there was an apparently reduced risk associated with the use of aspirin in hospital, as well as with the use of coumadin in hospital, in the two series for which these data were available.

For most risk indicators the association with intracranial haemorrhage was stronger among alteplase than among streptokinase recipients (table 2). For example, among patients treated with streptokinase, the dose indices (dose) body weight) in patients with intracranial haemorrhage and in controls were, respectively, 28409 (7012) and 30600 (6308) IU $/ \mathrm{kg}(\mathrm{p}=0.40)$. The corresponding dose indices for alteplase were $1.61(0.37)$ and $1.46(0.31) \mathrm{mg} / \mathrm{kg}(\mathrm{p}<0.01)$. After exclusion of TIMI II patients who received $150 \mathrm{mg}$ alteplase, the dose indices were $1.48(0.24) \mathrm{mg} / \mathrm{kg}$ and 1.37 $(0.21) \mathrm{mg} / \mathrm{kg}(\mathrm{p}<0.01)$.

Multivariate logistic regression analysis showed that four factors known at hospital admission were related to risk of intracranial haemorrhage-age over 65 years, weight under $70 \mathrm{~kg}$, hypertension on admission (systolic $\geqslant 170 \mathrm{~mm} \mathrm{Hg}$, diastolic $\geqslant 95 \mathrm{~mm} \mathrm{Hg}$, or both), and drug regimens with alteplase in the doses used. The results of this analysis were similar for patients who had all data available (not shown) as well as for 429 patients (including 143 with intracranial haemorrhage) who had complete data for the variables retained in the multivariate model (table 3 ). Exclusion of patients with subdural haematoma did not affect the results. The analysis was repeated in various subgroups. In 258 patients who received alteplase the odds ratios for age, low body weight, and hypertension were 3.2 $(1 \cdot 8-5 \cdot 6), 2 \cdot 5(1 \cdot 4-4 \cdot 4)$, and $2 \cdot 0(1 \cdot 0-3 \cdot 9)$, respectively. The corresponding odds ratios in 171 patients who received streptokinase were $1.3(0.7-2.0), 1.6(0.8-3 \cdot 1)$, and 1.9 $(0.9-4.0)$ (figure). Since the administration of $150 \mathrm{mg}$ alteplase has been linked to excessive intracranial bleeding, ${ }^{7}$ we repeated this analysis after exclusion of patients who received such therapy. In the remaining 220 alteplase 


\begin{tabular}{|c|c|c|c|c|}
\hline & \multicolumn{4}{|c|}{ Age (yr) } \\
\hline & $\overline{<65}$ & $66-75$ & $76-85$ & $>85$ \\
\hline \multicolumn{5}{|l|}{ Other rlsk factors* } \\
\hline 0 & 0.3 & 1.0 & 1.5 & $2 \cdot 3$ \\
\hline 1 & 10 & 13 & 20 & $2 \cdot 9$ \\
\hline 2 & 13 & 22 & $3 \cdot 3$ & 50 \\
\hline
\end{tabular}

Based on data in table 4 , with following assumptions: overall incidence of intracranial haemorrhage $=0.75 \%$; risk at ate $76-85$ is $50 \%$ greater than at age $66-75$; risk in patient

$>85$ years is again $50 \%$ greater than at $75-85$. *Hypertension on admisison, low body $>85$ years is again $50 \%$ gred

Table 5: Assessment of fisk of intracranial haemorrhage in different age groups

recipients the odds ratios were $3 \cdot 3(1 \cdot 8-6 \cdot 2), 2 \cdot 5(1 \cdot 4-4 \cdot 7)$, and $1 \cdot 6(0 \cdot 8-3 \cdot 4)$, respectively.

From the data in table 3, we developed a model to predict the risk of intracranial haemorrhage in an individual patient (tables 4 and 5). The odds ratios for the different risk factors were similar. Accordingly, these risk factors were given similar weights in the model and patients were grouped having one, two or three, and four risk factors. Assuming a $0.75 \%$ overall intracranial bleeding risk, the individual risk estimate varies from $0.26 \%$ for a patient without risk factors who received streptokinase to $5.0 \%$ for an elderly hypertensive patient with low body weight treated with alteplase.

\section{Discussion}

Haemorrhagic stroke accounts for $10-15 \%$ of all strokes in the general population. ${ }^{25,26}$ Risk factors for haemorrhagic stroke include advanced age, hypertension, trauma, vascular malformations, and the use of anticoagulants. ${ }^{25,27}$ Most trials of anticoagulant drugs have excluded patients thought to be at high risk of intracranial haemorrhage, either by protocol or by prudent physicians when established risk factors were recognised. Nevertheless, thrombolytic therapy seems to be associated with an increased incidence of intracranial haemorrhage, albeit with a concomitant reduction in embolic stroke rates. ${ }^{1,2}$ About half of all strokes after myocardial infarction are haemorrhagic when thrombolytic therapy is used. ${ }^{8,11}$

The risk factors for embolic stroke and intracranial bleeding differ. Patients at increased risk of embolic stroke, especially those with large anterior infarctions, should not be denied thrombolytic therapy. In fact, thrombolysis is specifically indicated for such patients, since it gives the greatest survival benefit in patients with larger infarcts. ${ }^{1-3}$ Limitation of infarct size and the thrombolytic effect do reduce the risk of left ventricular thrombi. On the other hand, risk factors for haemorrhagic stroke that can be recognised at hospital admission should be taken into account when a decision is made to administer a thrombolytic drug to a given patient.

Various features were found to be associated with the risk of intracranial haemorrhage in the studies included in our analysis. To obtain a larger database, the data were combined in our investigation. By multivariate logistic regression, four factors were independently associated with intracranial bleeding. Advanced age and high blood pressure are patient characteristics readily discernible before the decision on whether to give thrombolytic therapy is made. The associations with body weight and the use of alteplase mean that the choice of thrombolytic regimen must take into account the body size of a patient. Several other characteristics, which are known risk factors for intracranial haemorrhage in population studies, were associated with the disorder in univariate analysis but did not seem to have independent predictive value in multivariate analysis. For example, therapy with coumadin was associated with intracranial haemorrhage in the series from the Netherlands (odds ratio 3.7 [0.8-16.5]) where such therapy is practised in many patients with a previous infarction. ${ }^{10}$ Similarly, a history of peripheral vascular disease or diabetes is likely to be associated with intracranial haemorrhage, ${ }^{22}$ but these findings were rare and the associations were not powerful enough to appear in the multivariate analysis.

The association between age over 65 years and risk of intracranial haemorrhage was apparent even though some studies excluded patients over $70^{16,17}$ or over $75 .^{18-23}$ In larger population surveys of stroke, rates increase with age. ${ }^{28}$ In such surveys embolic or thrombotic strokes are most frequent, although few surveys make a distinction between different types of stroke. Accordingly, the data presented in table 5 were calculated with the assumption that risks for intracranial haemorrhage during thrombolytic therapy increase with age in the same way as total stroke risk in the population.

High blood pressure on admission was a stronger predictor of intracranial haemorrhage than a history of hypertension (table 2). This finding suggests that the bleeding risk depends not only on the state of the intracranial vessels, but also, and predominantly, on the actual blood pressure at the time of thrombolytic therapy. This notion is consistent with the observation that, at the time of hospital admission, more patients with intracranial haemorrhage than with other types of stroke showed high blood pressure. ${ }^{26}$ Prompt correction of high blood pressure is recommended in all infarct patients, but especially before or during thrombolytic therapy to reduce risk of bleeding.

Low body weight was associated with increased risk of intracranial haemorrhage in patients treated with alteplase. GISSI-2 and the International Study Group did not find an association between body-mass index and haemorrhagic or all strokes in patients receiving thrombolytic therapy. ${ }^{11}$ However, body-mass index is a measure of the extent of obesity, not actual weight or total body mass. Reanalysis of GISSI-2 and International Study Group data confirmed the association between intracranial haemorrhage risk and body weight for patients receiving alteplase, whereas no relation was observed in streptokinase recipients (A P Maggioni, M G Franzosi, personal communication). Weight-adjusted dosing for alteplase has been recommended previously, and has been introduced in clinical practice, ${ }^{21,22}$ although "front-loaded" alteplase regimens use a fixed dose schedule. ${ }^{29}$ Our analysis implies that weight-adjusted dosing should also be considered for streptokinase. Future analysis of data from the GUSTO study may help to resolve this issue. ${ }^{30}$

Previous studies showed that intracranial haemorrhage is more common among patients treated with "standard" doses of alteplase ${ }^{11}$ or duteplase ${ }^{2}$ than in those given streptokinase. These observations are supported by our analysis (table 3 ). These figures correspond to the actual drug regimens used in the studies. Alteplase was given in most patients as a fixed dose of $100 \mathrm{mg}$ over $3 \mathrm{~h}$. This dose was selected from studies that showed more rapid coronary reperfusion in comparison with lower doses and with standard streptokinase. ${ }^{31-33}$ It is not surprising that a regimen with greater thrombolytic efficacy results in more frequent side-effects, including intracranial haemorrhage. If patients are treated with alteplase, the bleeding risk can be reduced by lowering the dose. Administration of $50 \mathrm{mg}$ 
alteplase, for example, gives the same coronary reperfusion rate as $1.5 \mathrm{MU}$ streptokinase. ${ }^{31,32}$ However, the survival benefits of that regimen have not been established. Still, an increased risk of intracranial haemorrhage would be acceptable if the survival benefits of such an intensive regimen exceeded those of a more moderate streptokinase regimen. The net clinical benefit should be positive. In ISIS $-2,{ }^{2}$ the number of survivors without neurological sequelae was slightly higher (although not significantly so) in duteplase recipients than in streptokinase recipients. ${ }^{2}$ On the other hand, in GISSI-2 the net clinical benefit was somewhat greater for streptokinase. ${ }^{13,14}$ In the GUSTO trial, the greatest net clinical benefit was found for the accelerated alteplase regimen, despite a greater rate of intracranial haemorrhage in comparison with two streptokinase regimens. ${ }^{30}$

In addition to the thrombolytic agent, most patients receive an inhibitor of platelet aggregation (aspirin) as well as an anticoagulant (heparin, either intravenously or subcutaneously). In our analysis, neither aspirin nor heparin given in hospital was associated with risk of intracranial haemorrhage, probably because the study protocols delayed use of these drugs until several hours after thrombolysis. Obviously, aspirin and heparin would be withheld if signs of intracranial haemorrhage became apparent in the first hours after initiation of thrombolytic therapy.

\section{Risk assessment}

The model presented in tables 4 and 5 may help a doctor to estimate the risk of intracranial haemorrhage in a given patient. If the overall risk of intracranial haemorrhage is $0.75 \%$, the risk would be as low as $0.26 \%$ in patients without risk factors, who met the entry and exclusion criteria of the studies in this analysis. The probability of intracranial haemorrhage increased with the number of risk factors present. If the overall risk of intracranial haemorrhage is lower $(0.50 \%)$, the risks would be $0.88 \%$ and $1.43 \%$ in patients with two or three risk factors, respectively. The risks should be multiplied by 1.6 if the thrombolytic to be used is alteplase (figure).

This assessment of intracranial haemorrhage risk is somewhat crude, and does not account for factors that are likely to increase the risk although present in a smaller subgroup of patients, such as a history of extensive peripheral vascular disease, diabetes, and use of oral anticoagulants. The studies included enrolled patients younger than 75 years, with the exception of GISSI-2 and the International Study Group. Since the risk of intracranial haemorrhage increases with age, the risk in patients aged 75-85 years should be estimated as 1.5 times greater than that in patients of $65-75$ years and $50 \%$ higher again in patients above 85 years of age ${ }^{28}$ (table 5). Furthermore, in these and all other studies of thrombolysis, patients with recognised excessive risk of intracranial haemorrhage were excluded either by protocol, or by the doctors responsible for their treatment. Nevertheless, groups of patients with different risk profiles can be distinguished for individual clinical decision-making with the aid of our model

\section{Conclusion}

In patients with evolving myocardial infarction thrombolytic therapy salvages part of the myocardium at risk and improves survival. However, in a small number of patients thrombolytic therapy causes intracranial haemorrhage, which often results in death or disability. In each patient the doctor should estimate the potential benefits and risks of thrombolytic therapy. Earlier studies addressed the question of which patients will benefit from thrombolysis. ${ }^{6}$ This report identifies the factors associated with increased risk of intracranial haemorrhage-advanced age, hypertension upon admission, low body weight, and thrombolysis with current alteplase regimens. Thrombolytic therapy should nevertheless be given to elderly and hypertensive patients if the expected benefits are great-eg, in patients with extensive (anterior) ischaemia who can be treated soon after symptom onset. ${ }^{1-3,6}$ A careful evaluation of the applicability thrombolytic therapy is warranted in patients with several risk factors for intracranial haemorrhage.

We thank all investigators who contributed to the studies included in this report.

\section{Reference:}

1 Gruppo Italiano per lo studio della streptochinasi nell'infarto miocardico (GISSI). Effectiveness of intravenous thrombolytic treatment in acute myocardial infarction. Lancet 1986; i: 397-401.

2 ISIS-2 (Second International Study of Infarct Survival) collaborative group. Randomised trial of intravenous streptokinase, oral aspirin, both, or neither among 17187 cases of suspected acure myocardial infarction: ISIS-2. Lancet 1988; ii: 349-60.

3 Wilcox RG, Lippe G von der, Olsson CG, Jensen G, Skene AM. Hampton JR. Trial of tissue plasminogen activator for mortality reduction in acute myocardial infarction. Lancet 1988; ii: 525-30.

4 Simoons ML, Vos J, Tijssen JGP, et al. Long term benefit of early thrombolytic therapy in patients with acute myocardial infarction. f Am Coll Cardiol 1989; 14: 1609-15.

5 Vermeer F, Simoons ML, Zwaan C de, et al. Cost benefit analysis of early thrombolytic treatment with intracoronary streptokinase: twelve month follow up report of the randomized multicentre trial conducted by the Interuniversity Cardiology Institute of the Netherlands. Br Heart I 1988; 59: L527-34.

6 Vermeer F, Simoons ML, Bär FW. Which patients benefit most from early thrombolytic therapy with intracoronary streptokinase? Circulation 1986; 74: 1379-89.

7 Braunwald E, Knatterud GL, Passamani E, Solomon R. Update from the thrombolysis in myocardial infarction trial. $f$ Am Coll Cardiol 1987; 10: 970 .

8 Gore JM, Sloan M, Price TR, et al. Intracerebral hemorrhage, cerebral infarction, and subdural hematoma after acute myocardial infarction and thrombolytic therapy in the thrombolysis in myocardial infarction study. Circulation 1991; 83: 448-59.

9 Califf $R$, Topol EJ, George BS, et al. Hemorrhagic complications associated with the use of intravenous tissue plasminogen activator in treatment of acute myocardial infarction. Am $\mathcal{Y}$ Med 1988; 85; 33353-59.

10 Jaegere PP de, Arnold AA, Balk AH, Simoons ML. Intracranial hemorrhage in association with thrombolytic therapy: incidence and clinical predictive factors. 7 Am Coll Cardiol 1992; 19: 289-94.

11 Maggioni AP, Franzosi MG, Santoro E, et al. Gruppo Italiano per lo Studio della sopravvivenza nell'Infarto Miocardico II (GISSI-2), and the International Study Group. The risk of stroke in patients with acute myocardial infarction after thrombolytic and antithrombolytic treatment. N Engl F Med 1992; 327: 1-6.

12 Kase CS, Pessin MS, Zivin JA, et al. Intracranial hemorrhage after coronary thrombolysis with tissue plasminogen activator. Am 9 Med 1992; 4: 384-90.

13 The International Study Group. In-hospital mortality and clinical course of 20891 patients with suspected acute myocardial infarction randomised between alteplase and streptokinase with or without heparin. Lancet 1990; 336: 71-75.

14 Gruppo Italiano per lo studio della Soprovvivenza nell'infarto miocardico. GISSI-2: a factorial randomised trial of alteplase versus streptokinase and heparin versus no heparin among 12490 patients with acute myocardial infarction. Lancet 1990 ; 336: 65-71.

15 ISAM Study Group. A prospective trial of intravenous streptokinase in acute myocardial infarction (ISAM): mortality, morbidity, and infarct size at 21 days. $N$ Engl $f$ Med 1986; 314: 1465-71. 
16 Werf F van de, Arnold AER. Intravenous tissue plasminogen activator and size of infarct, left ventricular function and survival in acute myocardial infarction. BMF 1988; 297: 1374-79.

17 Simoons ML, Arnold AER, Bertriu A, et al. Thrombolysis with tissue plasminogen activator in acute myocardial infarction: no additional benefit from immediate percutaneous coronary angioplasty. Lancet 1988; i: 197-203.

18 Passamani E, Hodges $M$, Herman $M$, et al. The Thrombolysis in Myocardial Infarction (TIMI) phase II pilot study: tissue plasminogen activator followed by percutaneous transluminal coronary angioplasty. f Am Coll Cardiol 1987; 10: 51B-64B.

19 TIMI Study Group. Comparison of intensive and conservative strategies after treatment with intravenous tissue plasminogen activar in acute myocardial infarction: results of the thrombolysis in myocardial infarction (TIMI) phase II trial. $N$ Engl F Med 1989; 320: 618-27.

20 Topol EJ, Califf RM, George BS, et al. A randomized trial of immediate versus delayed elective angioplasty after intravenous tissue plasminogen activator in acute myocardial infarction. $N$ Engl $f \mathrm{Med}$ 1987; 317: 581-88.

21 Topol EJ, Califf RM, George BS, et al, and the TAMI Study Group. Coronary arterial thrombolysis with combined infusion of recombinant tissue-type plasminogen activator and urokinase in patients with acute myocardial infarction. Circulation 1988; 77: 1100-07.

22 Topol EJ, George BS, Kereiakas DJ, et al, and the TAMI Study Group. A randomised controlled trial of intravenous heparin in acute myocardial infarction. Circulation 1989; 79: 281-86.

23 Wall TC, Califf RM, George BS, et al. TAMI 7 study group. Accelerated plasminogen activator dose regimens for coronary thrombolysis. f Am Coll Cardiol 1992; 19: 482-89.
24 Bossuyt PMM, Lubsen J. Klinische Besliskunde (Medical decision analysis). Amsterdam: Vantree Medical Services, 1990: 127-29.

25 Caplan LR. Intracerebral haemorrhage. Lancet 1992; 339: 656-58.

26 Herman B, Leyten ACM, Van Luijk JH, Frenken CWGM, Op de Coul AAW, Schulte BPM. Epidemiology of stroke in Tilburg, the Netherlands: the population-based stroke incidence register: 2 incidence, initial clinical picture and medical care, and three-week case fatality. Stroke 1982; 13: 629-34.

27 Marmot MG, Poulter NR. Primary prevention of stroke. Lancet 1992; 339: 344-47.

28 Bonita R. Epidemiology of stroke. Lancet 1992; 339: 342-44.

29 Neuhaus KL, Feuerer W, Jeep-Tebbe S, et al. Improved thrombolysis with a modified dose regimen of recombinant tissue type plasminogen activator. F Am Coll Cardiol 1989; 14: 1566-69.

30 The GUSTO Investigators. An international randomized tria comparing four thrombolytic strategies for acute myocardial infarction. $N$ Engl f Med 1993; 329: 673-82.

31 Verstraete $M$, Bory $M$, Collen $D$, et al. Randomised trial of intravenous recombinant tissue-type plasminogen activator versus intravenous streptokinase in acute myocardial infarction. Lancet 1985; i: $842-47$.

32 Chesebro JH, Knatterud G, Roberts $R$, et al. Thrombolysis in myocardial infarction (TIMI) trial, phase I: a comparison between intravenous tissue plasminogen activator and intravenous streptokinase. Circulation 1987; 76: 142-54.

33 Mueller HS, Koneti Rao A, Forman SA, and the TIMI investigators. Thrombolysis in myocardial infarction (TIMI): comparative studies of coronary reperfusion and systemic fibrinogenolysis with two forms of recombinant tissue-type plasminogen activator. $\mathcal{F} \mathrm{Am}$ Coll Cardiol 1987; 10: 479-90.

\title{
Moclobemide
}

\author{
Hugh Freeman
}

\section{Background}

To understand the development of moclobemide, a selective monoamine oxidase inhibitor (MAOI) for use in depression, we need to consider its origins in antituberculosis drugs. Thus, iproniazid was noted to cause euphoria ${ }^{1}$ in tuberculous patients, but this reaction was thought to be a response to their poor physical state. Kline's proposal $^{1}$ that these drugs were in fact antidepressant was an important landmark in psychiatry, since the only effective treatment for depression until then was electroconvulsive therapy. Their action in brain led to the agents being described as MAOIs; they came into clinical use in 1959, the same year as the first tricyclic antidepressant (TCA), imipramine.

Iproniazid had to be withdrawn because of an association with acute hepatic necrosis (the mechanism of which is still unclear) and was replaced by isocarboxacid and phenelzine. In the 1960s the toxic effects resulting from absorption of dietary tyramine ("cheese reaction") became apparent; this reaction was the result of inhibition of intestinal MAO, which can provoke a hypertensive crisis. Tranylcypromine (a non-hydrazine MAOI related to amphetamine) was the most troublesome drug in this respect but also the most efficacious. In addition, MAOIs were incompatible with

UnWersity of Salford, Salford, UK (Prof Hugh Freeman FFCPsych) Correspondence to: Prof Hugh Freeman, 21 Montagu Square, London W1H 1RE, UK drugs containing indirectly acting sympathomimetic agents and with most forms of alcohol.

Two early trials showed that results with phenelzine were not significantly different from those with placebo in depressed patients, but the experience of many clinicians was far more positive and the trial results may have come about because the maximum dose was too low and the period of treatment too short. Because MAOIs then had to be prescribed with dietary and other restrictions interest shifted away, and their clinical use virtually ceased in most countries. However, some researchers proposed that "atypical" forms of depression responded better to MAOIs than to TCAs. Although the evidence remains uncertain, there is no doubt that individuals vary in their response to antidepressants, and that some with typical endogenous depression who do badly with TCAs may be greatly improved by MAOIs. This response may be related to the fact that MAOIs increase blood concentrations of serotonin, whereas TCAs lower them. ${ }^{2}$ Inhibition of MAO decreases the metabolism of noradrenaline and serotonin, leading to increased concentrations of these neurotransmitters. MAOIs have also been shown effective in controlling anxiety disorders, but this action has not been evaluated adequately.

The classic MAOIs were irreversible in that body concentrations of MAO did not return to normal until 2 weeks after the end of treatment because new enzyme had to be synthesised. Consequently, drugs that might cause toxic interactions, including TCAs, could not be introduced 